\title{
Per Millisecond
}

National Cancer Institute

\section{Source}

National Cancer Institute. Per Millisecond. NCI Thesaurus. Code C161490.

A unit of time, which is equal to the reciprocal of one thousandth of a second. 